\title{
Making the Grade: Evaluating the Construct Validity of MyPsychLab as a Measure of Psychology Mastery
}

\author{
Kenneth M. Cramer, Craig Ross, Emily S. Orr, Ann Marcoccia \\ Department of Psychology, University of Windsor, Windsor, Canada \\ Email: KCramer@UWindsor.CA
}

Received September 2 $2^{\text {nd }}$, 2011; revised October 18 $8^{\text {th }}, 2011$; accepted November $2^{\text {nd }}, 2011$

\begin{abstract}
Publishers of resources for secondary and post-secondary education are becoming more innovative in developing tools for mastery of the course material. Pearson Education Inc.'s MyPsychLab is an example of such a tool. MyPsychLab consists of online exercises, flashcards, and demonstrations; but also includes pretest and posttest assessment tools (which can be taken repeatedly until mastery is reached). Given this tool promotes material mastery, it is expected that MyPsychLab performance would be related to course performance in more traditional formats. The present study investigated the relation between MyPsychLab, and five additional means of course assessment in a large sample of students enrolled in an introductory Psychology course. Results indicated that MyPsychLab was significantly correlated with all other measures of course performance. Moreover, performance on MyPsychLab was the highest loading item on both a latent component and factor assessing overall course performance and psychology mastery.
\end{abstract}

Keywords: Online Learning Environments; MyPsychLab; Material Mastery

\section{Introduction}

One of the most significant challenges facing instructors of large university classrooms is the provision of effective feedback to facilitate student learning. Very often, the only feedback students receive in these types of classes comes in the form of summative assessment-a method of testing knowledge at the end of a course or unit that is primarily intended to determine a student's grade (Wininger, 2005). From the perspective of a student, however, summative assessment feedback is "too little, too late" because the feedback appears as a final grade at the conclusion of the semester.

In order to enhance student learning throughout the course, some instructors attempt to include formative assessment feedback in their courses. Unlike summative feedback, formative feedback is intended to provide information that students can use to gauge their level of mastery, which can be used to focus (and perhaps alter) students' study strategies (Buchanan, 2000). The rationale for formative feedback, therefore, is to provide students with feedback on their knowledge or skills while an opportunity remains to make changes to their study strategies to broaden and deepen their understanding and mastery of the course material (Brown \& Knight, 1994). In smaller courses, this kind of feedback can often be provided by the instructor or teaching assistant. However, in especially large classes (over 250 students), a different approach is needed.

With the proliferation of the Internet and the evolution of multimedia and informational tools, there has been greater emphasis placed on the use of web-based learning resources to provide opportunities for formative assessment (Wang, Wang, Wang, \& Huang, 2006). Generally, web-based learning tools for postsecondary education take the form of an online quiz, followed by feedback and suggested learning resources. Some programs, such as PsyCAL, do not provide correct answers (Buchanan, 1999), although many others do. In addition to offering students the opportunity to receive feedback about their progress in a course, this type of formative assessment can also encourage students to develop greater feelings of responsibility and accomplishment in a course, which may foster greater motivation and preparation (Deeprose \& Armitage, 2004).

As a publisher of both secondary and post-secondary education materials, Pearson Education Inc. has produced a variety of pedagogical tools designed to increase student mastery of the assigned material in various university and college disciplines. These tools tap a variety of subjects including art and language, sciences, and social sciences. Of interest in the present study is the extent to which these tools tap skills relevant to the subject matter, or whether they are empirically separate from other more standard methods of measuring student mastery of course material (e.g., tests and assignments). We will specifically evaluate, in the context of a large introductory psychology course, the construct validity of MyPsychLab.

One especially useful theoretical framework for understanding the benefits of these types of online systems is Vygotsky's Zone of Proximal Development, which describes an individual's capabilities when facilitated by a more skilled other (Wertsch \& Tulviste, 1992). Traditionally, the "other" is a person who is more experienced in a particular domain. However, tools like $M y$ PsychLab can serve as the more skilled other by providing timely feedback and allowing students to learn from their mistakes. In this way, it is possible to conceive an individual's cognitive potential as greater than what s/he can directly express on a traditional multiple-choice or short-answer exam.

Typical of contemporary tools such as MyPsychLab (www. mypsychlab.com), students enter an online learning environment that offers the opportunity to review and practice (for each chapter) their personal mastery and understanding of the course material. A calendar highlights weekly assignments of a given module, unit, or chapter, consisting of three parts: pretest, study plan, and posttest. To begin, students are directed to a pretest 
that initially assesses their current understanding of the material. The pretest consists of 20 - 25 multiple choice questions based on the chapter contents, and renders students a pretest score based on their responses. Students can review the items, with correct answers revealed for any mistakes. MyPsychLab then creates a unique study plan, specific to the areas of needed improvement based on that student's pretest profile (i.e., brain anatomy modules such as flashcards, quizzes, and demonstrations may be included if many or all of these pretests items were answered incorrectly). Specific segments of the textbook are also included in order that students can locate and review the necessary materials. After study plan has been reviewed, students may proceed to the posttest, consisting of 20 - 25 questions (different from those in the pretest, but common for all students). A summary score is derived, and students can review individual items; however, correct answers are not in this case revealed. Students can return to the study plan for further review, and attempt the same posttest to improve their score. MyPsychLab will record (in an instructor's gradebook) students' last posttest mark prior to the posted deadline. In this way, students can receive continual feedback about their learning performance, and more easily identify areas of weakness.

Instructors often include this type of tool as a learning resource, assuming it should predict performance on both tests and assignments. Previous research has supported this notion. For example, Wininger (2005) observed an increase of $10 \%$ on final exam scores among students who received a form of formative assessment after a midterm exam. Similarly, Buchanan (2000) observed higher performance on final exams among students who made use of PsyCAL web-based software. However, the empirical evidence is not entirely positive regarding the use of formative feedback and web-based tool. In their study of formative assessment, Gijbels and Dochy (2006) observed a shift to more surface-level thinking and learning practices among students who received weekly feedback from an instructor about their progress in the course of learning new concepts. Likewise, researchers reported no significant relation between performance on the final examination and students' use of MyMathLab (Tzufang, 2009). However, since Tzufang's research utilized a Math-based curriculum (as opposed to a subject with numerous domains within a myriad of theoretical frameworks), there is reason to believe the software may have been ineffective because of limited opportunities for feedback and assistance.

Despite the various challenges observed in the use of formative assessment, we assumed in the present study that the use of an online tool such as MyPsychLab can provide students with the kind of practice, reinforcement, and feedback that would prove helpful in mastering introductory level material. Using an especially large sample of students and a variety of means to assess student mastery and performance, it was hypothesized that MyPsychLab would both correlate with and render acceptable reliability coefficients among other performance measures.

\section{Method}

\section{Participants and Measures}

The present sample consisted of 1251 (851 females, 68\%) students at the University of Windsor in Southwestern Ontario, Canada; enrolled in an introductory psychology course for the
January 2009 semester. The course utilized six media toward the derivation of student performance in the course: 1) a 120item multiple choice test (worth $35 \%$ of the course grade) based on the first 4 chapters covered in the semester (child development, adulthood and aging, cognition, and intelligence); 2) a 120-item multiple choice comprehensive final examination (40\%), which included past material covered in the midterm but emphasized recent coverage of social and applied psychology, personality, psychopathology, and treatment of mental disorders; 3) MyPsychLab (10\%) based on the completion of 9 chapter post-tests, one of which (the applied psychology chapter) was given double the weight to yield a score out of 10 ;4) a peer-review assignment (10\%), wherein students complete a 1 2 pages written assignment graded by fellow students; 5) a class participation mark using electronic voting devices or clickers (5\%). Whereas these five measures yielded $100 \%$ of the grade, students had the opportunity; 6) to earn three bonus marks in the course through participation in ongoing psychology research.

\section{Results}

Table 1 shows the intercorrelations (all significant at $p<.05$, $\mathrm{df}=1249$ ) among the six measures. Using Pearson product moment correlations, students' MyPsychLab correlations to the other measures ranged from .299 (course midterm) to .488 (clicker). A reliability analysis, using standardized transformations of the six measures, showed a Cronbach's alpha coefficient of .76, with moderate item-total correlations (see Table 1) for each measure, suggesting they each contributed to measurement of the construct (though arguably less so for the research bonus marks).

Given the large number of participants, the data were analyzed using each of two data reduction methods. First, we utilized a principal components analysis, wherein the relative contribution of each measure was assumed to be equal (with diagonal communalities set to unity). This method extracted one component (rendering rotation unfeasible), explaining $46 \%$ of the shared variance. Examination of the component matrix (see Table 1) showed that MyPsychLab was the highest contributor to the single latent component (.734). Secondly, we utilized a principal axis factor analysis wherein the relative contribution of each measure was not assumed to be equal (with diagonal entries set to prior communality estimates). This method also extracted one factor, explaining 35\% of the shared variance. Examination of the factor matrix showed that MyPsychLab was the highest contributor to the single latent factor (.667).

\section{Discussion}

Overall, the present study supported the construct validity of the MyPsychLab resource in four ways. To begin, students' MyPsychLab scores were correlated (mildly to moderately) with each of the other five measures of student performance. Secondly, each of the six measures contributed to a general construct as demonstrated by a cohesive reliability coefficient. In other words, the items measured a similar construct. The most convincing evidence however was obtained using both principal component and principal axis factoring, which rendered comparable results: a unitary construct emerged within the data, with the highest contribution offered from $M y P$ sychLab, and smaller (but still substantial) contributions offered from other measures of student performance. Future studies 


\section{K. M. CRAMER ET AL.}

Table 1.

Measure intercorrelations, item-total correlations, and component factor loadings.

\begin{tabular}{|c|c|c|c|c|c|c|c|c|}
\hline & MPL & Mid & Exam & Peer & Click & Bonus & Mean & SD \\
\hline MyPsychLab & 1.00 & & & & & & 7.75 & 2.79 \\
\hline Midterm & .299 & 1.00 & & & & & .61 & .12 \\
\hline Examination & .347 & .714 & 1.00 & & & & .65 & .14 \\
\hline Peer Review & .423 & .349 & .356 & 1.00 & & & 7.05 & 2.26 \\
\hline Clicker & .488 & .278 & .285 & .358 & 1.00 & & 3.48 & 1.57 \\
\hline Bonus & .354 & .206 & .224 & .263 & .285 & 1.00 & 1.60 & 1.43 \\
\hline Item Total Correlations & .56 & .54 & .57 & .51 & .49 & .37 & & \\
\hline Component Loadings & .734 & .706 & .663 & .688 & .723 & .540 & & \\
\hline Factor Loadings & .667 & .626 & .571 & .593 & .652 & .434 & & \\
\hline
\end{tabular}

Note: All correlations are significant at $p<.05$.

would do well to conduct comparable studies in other subjects, across both sciences and languages, composition and mathematics.

\section{REFERENCES}

Brown, S., \& Knight, P. (1994). Assessing learners in higher education. London: Kogan Page.

Buchanan, T. (2000). The efficacy of a World-Wide Web mediated formative assessment. Journal of Computer Assisted Learning, 16, 193200. doi:10.1046/j.1365-2729.2000.00132.x

Deeprose, C., \& Armitage, C. (2004). Reports: Giving formative feedback in higher education. Psychology Learning and Teaching, 4, 4346. doi:10.2304/plat.2004.4.1.43

Gijbels, D., \& Dochy, F. (2006). Students' assessment preferences and approaches to learning: Can formative assessment make a difference? Educational Studies, 32, 399-409. doi:10.1080/03055690600850354 Tzufang, H. (2009). The role of task-specific adapted knowledge of response feedback in algebra problem solving online homework in a college remedial course. Doctoral Dissertation, Los Angeles: University of Southern California.

Wang, K. H., Wang, T. H., Wang, W. L., \& Huang, S. C. (2006). Learning styles and formative assessment strategy: Enhancing student achievement in web-based learning. Journal of Computer Assisted Learning, 22, 207-217. doi:10.1111/j.1365-2729.2006.00166.x

Wertsch, J. V., \& Tulviste, P. (1992). L. S. Vygotsky and contemporary developmental psychology. Developmental Psychology, 28, 548-557. doi:10.1037/0012-1649.28.4.548

Wininger, S. R. (2005). Using your tests to teach: Formative assessment. Teaching of Psychology, 32, 164-166. doi:10.1207/s15328023top3203 7 